\section{Oxygen Inhibition of Surface Composites and Its Correlation with Degree ofConversion and Color Stability}

Marcela Gonçalves Borges ${ }^{1} \oplus$, Gisele Rodrigues Silva ${ }^{1}{ }^{\circ}$, Fernanda Teodoro Neves ${ }^{1} \oplus$, Carlos José Soares ${ }^{1} \oplus$, André Luís Faria-e-Silva ${ }^{2} \odot$, Roberta Furtado Carvalho $^{3}$ 이, Murilo Sousa Menezes ${ }^{1}$ 두
1Department of Operative Dentistry and Dental Materials, Dental School, UFU - Universidade Federal de Uberlândia, Uberlândia, MG, Brazil ${ }^{2}$ Department of Dentistry, School of Dentistry, UFS - Universidade Federal de Sergipe, Aracaju, SE, Brazil ${ }^{3}$ Department of Operative Dentistry and Dental Materials, School of Dentistry, Universidade CEUMA, São Luís, MA, Brazil

Correspondence: Gisele Rodrigues da Silva, Avenida Pará, 1720, Bloco 4L, Anexo A, 3o Piso, Sala 33, 38405320 Uberlândia, MG, Brasil. Tel: +55-34-3225-8106. e-mail: giselerosilva@ufu.br
This study investigated the effects of oxygen inhibition and finishing/polishing procedure on the composite resin properties. One bulk-fill and two conventional composite resins (nanoparticle and microhybrid) were evaluated. Specimens were prepared using 4 surface treatments: control, no treatment; Gly, oxygen inhibition with glycerin; FP, finishing and polishing; Gly + FP, glycerin followed by finishing and polishing. The degree of conversion (DC) was measured using Fourier Transformed Infrared Spectroscopy (FTIR) immediately and after 15 days $(n=5)$. Color stability $\left(\Delta \mathrm{E}_{a b}\right.$, and $\left.\Delta \mathrm{E}_{00}\right)$ and opacity were evaluated using a spectrophotometer after 15 days of immersion in coffee, using the CIELAB system $(n=5)$. Data were analyzed by two-way ANOVA and Tukey tests $(\alpha=0.05)$ and opacity by two-way repeated-measures ANOVA. Glycerin usage increased significantly the DC however had no influence on the $\Delta \mathrm{E}_{\mathrm{ab}}, \Delta \mathrm{E}_{00}$ and, opacity values. Finishing and polishing reduced $\Delta \mathrm{E}_{\mathrm{ab}}$ and $\Delta \mathrm{E}_{00}$ values, regardless of composite resins. Microhybrid showed higher opacity, followed by the nanoparticle and bulk fill, regardless of surface treatment. Post-polymerization polishing procedures resulted in lower conversion than using an oxygen inhibitor agent (Gly condition), but similar staining caused by coffee.
Key Words: composite resin, oxygen inhibition, finishing and polishing, color change, degree of conversion.

\section{Introduction}

Composite resins are materials widely used in daily practice that need adequate polymerization for good clinical performance (1). These materials are undergoing chemical degradation processes in the oral cavity due to diets that contain staining solutions, as well as acidic foods and drinks $(2,3)$. Degradation of composite resin, including color alteration, may result in additional costs due to early replacement of restorations. The degree of conversion (DC) of monomers is measured by the percentage of double bonds of carbon consumed during the polymerization reaction (1). The DC depends on the emission spectra of light curing units to match the absorption spectra of the photoinitiators used in these materials. Additionally, the light must actually reach all area of the restoration (4).

During composite light-curing, the contact of oxygen produces a surface layer of uncured resin $(5,6)$. The oxygen inhibits the polymerization reaction, resulting in the formation of a polymer chain more prone to staining and wearing (5). The oxygen-inhibited layer thickness for composite resins ranges from $4 \mu \mathrm{m}$ to $40 \mu \mathrm{m}$ (5). The thickness of the oxygen-inhibited layer depends on the type of monomer, initiator-activator systems, particle morphology, concentration of free radicals, and the oxygen consumption rate $(5,6)$. Some clinicians have applied glycerin gel or water-soluble gel over the last increment light-curing trough the transparent layer avoiding the oxygen inhibition of composite resin surface $(5,6)$.

Nowadays, microhybrid and nanoparticle composites are considered universal resin-based restorative materials suitable for the restoration of anterior and posterior teeth due to their excellent aesthetic properties. These nanomaterials use submicrometre particles to further enhance the optical and physical properties of the resins (3). Bulk fill composite resin, flowable and higher viscosity, claim to enable the posterior restoration of build-up in thick layers, 4 to $5 \mathrm{~mm}$, reaching adequate polymerization in deeper regions $(4,7-9)$. Sufficient depth of cure may be achieved by using specific polymerization modulators, by improving the translucency, or by using more potent initiator systems. Restoring posterior cavities using bulkfill composite resins can result in reduced shrinkage stress and cusp deflection, which might improve the clinical performance of the restoration (10)

To the best of our knowledge, the literature is scarce in terms of the ideal moment to perform surface finishing and polishing procedures of composite resins modulated by presence of unpolymerized monomers on the surface. This condition could absorb pigments, especially on the difficult to access areas such as the proximal surface or occlusal surface of posterior teeth. Moreover, the effects of glycerin use over composite resin surfaces are not clear in relation the mechanical properties improvement. Therefore, the aim of this study was to investigate the effects of 
oxygen inhibition and finishing/polishing procedures on the degree of conversion (DC) and color stability $\left(\Delta \mathrm{E}_{\mathrm{ab}}, \Delta \mathrm{E}_{00}\right.$ and opacity) of bulk-fill and conventional composite resins. The null hypothesis was that the use of the glycerin oxygen inhibitor gel or its association with immediate finishing and polishing would not improve the color stability and the degree of cure of bulk-fill or conventional composite resins.

\section{Material and Methods}

\section{Experimental Design}

This in vitro investigation was conducted using a $3 \times 4 \times 2$ factorial study design to evaluate the factors "composite resin - bulk-fill, conventional nanoparticle and microhybrid", "protocols of surface treatments- no treatment, oxygen inhibition with glycerin, finishing and polishing, and glycerin + finishing and polishing" and "assessment time - immediate and mediate analysis". The main response variables included in this study were [1] degree of conversion and [2] color change.

\section{Specimen Preparation}

One bulk-fill (Filtek Posterior Bulk-Fill, 3M ESPE, St, Paul, MN, USA), and two conventional nanoparticle (Filtek Z350 XT, 3M ESPE) and microhybrid (Filtek Z250, 3M ESPE) composite resins were evaluated in this study. The compositions of materials used are described in Table 1. To measure the DC, according to the International Standards Organization (ISO) 4049, the composite resins were inserted into a silicone mold (HydroXtreme, Vigodent, Rio de Janeiro, Rio de Janeiro, Brazil) with internal dimensions of $4 \mathrm{~mm}$ in diameter $\times 2 \mathrm{~mm}$ of thickness. Specimens for color measurement (ISO/TR 28642) were built-up using a Teflon mold ( $8 \mathrm{~mm}$ of diameter $\times 2 \mathrm{~mm}$ of depth).

A halogen-light-based curing unit (OptiLux 501, Demetron, Danbury, CT, USA - $600 \mathrm{~mW} / \mathrm{cm}^{2}$ ) was fixed in a standard device in order to maintain a fixed distance between the light-curing tip and sample surface. After placing the material into the mold, a polyester strip was pressed over the surface with a glass slab to obtain a flat surface. After the glass slab and the strip were removed and the photoactivation was made for $20 \mathrm{~s}$, perpendicular and directly on the top of the specimens, at the shortest possible standardized position between the tip and the mold. Specimens were prepared according to different surface treatments:

Control group (Control): the composite resins were light-cured for an additional $20 \mathrm{~s}$.

Glycerin surface treatment (Gly): glycerin (Biopharma, Uberlândia, MG, Brazil) was applied on the surface of composite resin specimens followed by additional light activation for $20 \mathrm{~s}$.

Finishing and polishing (FP): the composite resin specimens were light-cured for an additional $20 \mathrm{~s}$, followed by finishing and polishing with abrasive disc Sof-Lex Pop-On (3M/ESPE) used sequentially according to the abrasiveness (medium, fine, and extra-fine discs). Ten movements were performed for each disc. The surface of the specimen was cleaned with distilled water and the composite resin surface was polished with a polishing paste Fotoacrill (Dhpro, Paranaguá, Paraná, Brazil) associated with a felt disk Diamond (FGM, Joinville, Santa Catarina, Brazil). The felt disk was wiped on the surface of the sample with alcohol 70\% (Itajá, Goianésia, Goiás, Brazil) with friction and dried with an air-stream for $10 \mathrm{~s}$ following each procedure.

Glycerin + finishing + polishing $(G / y+F P):$ after glycerin surface application and light activation for 20 $\mathrm{s}$, the finishing and polishing were performed using the previously described protocol.

Five specimens were produced with the same finishing/ polishing instrument. Before DC analysis, 70\% alcohol with gauze was used with on the specimens to remove the glycerin and post polishing compounds. The same clean protocol was used for control group.

\section{Degree of Conversion Measurement}

The specimens were placed on the ATR crystal directly with standardized pressure by the ATR device. The DC was measured immediately after the finishing and polishing surface procedures and again after 15 days using Fourier

Table 1. Materials used (information provided by the manufacturers)

\begin{tabular}{|c|c|c|}
\hline Composite resin & Type & Composition* (weight\%/volume\%) \\
\hline Filtek Posterior Bulk-Fill & Bulk-Fill & $\begin{array}{l}\text { Aromatic UDMA, UDMA, silica, DDDMA, silane treated ceramic, } \\
\text { pentanedioic acid, 2,2-dimethyl-4-methylene-reaction products with } \\
\text { glycidyl methacrylate, EDMAB, benzotriazol, titanium dioxide. Shade A3 }\end{array}$ \\
\hline Filtek Z350 XT & Conventional nanoparticle & $\begin{array}{l}\text { Bis-GMA, UDMA, Bis-EMA, PEGDMA, TEGDMA resins, combination of } 20 \mathrm{~nm} \\
\text { silica filler, } 4 \text { to } 11 \mathrm{~nm} \text { zirconia filler, zirconia/silica cluster filler. Shade A3E }\end{array}$ \\
\hline Filtek Z250XT & Conventional microhybrid & $\begin{array}{l}\text { Bis-GMA, TEGDMA, UDMA, Bis-EMA, aluminum oxide, EDMAB, } \\
\text { silane treated ceramic, initiators, stabilizers, pigments. Shade A3 }\end{array}$ \\
\hline
\end{tabular}

*Bis-GMA: bisphenol glycidyl methacrylate; UDMA: urethane dimethacrylate; TEGDMA: triethylene glycol dimethacrylate; PEGDMA: polyethylene glycol dimethacrylate; Bis-EMA: ethoxylated bisphenol-A dimethacrylate; DDDMA: 1,12-dodecane dimethycrylate; EDMAB: ethyl 4-dimethyl aminobenzoate. All composite resin was manufactured by 3M/ESPE. 
Transformed Infrared Spectroscopy (FIIR-Vertex 70, Bruker Optik $\mathrm{GmbH}$, Ettlingen, Germany). For the evaluation after 15 days, specimens were stored in a dry and dark container at $37^{\circ} \mathrm{C}$. The DC was assessed using FTIR with attenuated total reflectance (ATR crystal) sampling, mid-infrared (MIR) and deuterated triglycine sulfate (DTGS) detector elements (Bruker Optik), with a $4 \mathrm{~cm}^{-1}$ resolution and coaddition of 32 scans. All analyses were performed under controlled temperature $\left(25 \pm 1^{\circ} \mathrm{C}\right)$ and humidity $(60 \pm 5 \%)$ conditions. The DC was calculated from the equivalent aliphatic (1640 $\left.\mathrm{cm}^{-1}\right)$ and aromatic $\left(1610 \mathrm{~cm}^{-1}\right)$ of cured (C) and uncured (U) composite resin specimens according to the following equation: $D C=(1-C / U) \times 100$.

\section{Immersion of Coffee and Color Stability Measurement $(N=5)$}

The color analysis was carried out immediately after specimen preparation. After $24 \mathrm{~h}$ of specimens being stored in a dry and dark container at $37^{\circ} \mathrm{C}$, they were individually immersed in $1 \mathrm{~mL}$ of coffee solution (Nestlé, São Paulo, SP, Brazil) for 15 days at $37^{\circ} \mathrm{C}$ (9). The solution was replaced daily. After storing, the excess of the solution was removed, and the specimens were ultrasonically (UItrasonic Cleaner, Thornton - INPEC, Vinhedo, SP, Brazil) washed in distilled water for $10 \mathrm{~min}$ and dried.

The readings assessed at baseline were used to calculate the color changes caused by coffee immersion. The baseline color coordinates were assessed in standard conditions by means of a reflectance spectrophotometer (Ci64UV, Xrite, Chandler, Arizona, USA). The device was adjusted for the D65 light source, with $100 \%$ ultraviolet and specular reflection included. The observer angle was set at 10 degrees, and the device was adjusted to a small reading area (SAV), with a total area of $4 \mathrm{~mm}^{2}$. The color parameters were measured over white background (L*white $85.6, a^{*}$ white $1.28, b^{*}$ white 6.83) while the opacity was directly measured by the device. To measure opacity, samples were made against white, black (L*black 26.32, a*black -38, b*black 0.53), and white backgrounds again (11). The spectrophotometer was adjusted for three consecutive readings, which were later averaged. The opacity was calculated by the contrast ratio from the luminous reflectance $(Y)$ of the specimens with a black $(\mathrm{Yb})$ and a white $(\mathrm{Yw})$ backing. A value of $\mathrm{Yb} / \mathrm{Yw}=0$ means that the specimen is completely transparent, and $\mathrm{Yb} /$ $Y w=100$ implies that the specimen is completely opaque.

The results of the color readings were quantified in terms of the $L^{*}, a^{*}$, and $b^{*}$ coordinate values established by the Commission Internationale de l'Eclairage (CIELAB system). The color difference of the same specimen was calculated by the use of two different equations. The first one is the CIELAB color difference $\left(\Delta \mathrm{E}_{\mathrm{ab}}\right)$ equation, which was calculated as follows: $\Delta \mathrm{E}_{\mathrm{ab}}=\left(\Delta \mathrm{L}^{2}+\Delta \mathrm{a}^{2}+\Delta \mathrm{b}^{2}\right)^{1 / 2}$ where
$\Delta \mathrm{L}^{*}, \Delta \mathrm{a}^{*}$, and $\Delta \mathrm{b}^{*}$ refers to lightness, green-red, and blueyellow differences of baseline and post coffee immersion color measurements. The second is the CIEDE2000 color difference $\left(\Delta \mathrm{E}_{00}\right)$, and it was calculated as follows: $\Delta \mathrm{E}_{00}=$ $\left[\left(\Delta \mathrm{L} / \mathrm{KLS}+(\Delta \mathrm{C} / \mathrm{KCSC})^{2}+(\Delta \mathrm{H} / \mathrm{KHSH})^{2}+\mathrm{RT}(\Delta \mathrm{C} / \mathrm{KCSC})(\Delta \mathrm{H} /\right.\right.$ $\mathrm{KHSH})]^{1 / 2}$.where $\Delta \mathrm{L}, \Delta \mathrm{C}$ and $\Delta \mathrm{H}$ are considered lightness, chroma, and hue differences between color measurements. $\mathrm{KL}, \mathrm{KC}$, and $\mathrm{KH}$ are the parametric factors for viewing conditions and illuminating conditions influence. $\mathrm{RT}$ is the function for the hue and chroma differences interaction in the blue region. $\mathrm{SL}, \mathrm{SC}$, and $\mathrm{SH}$ are the weighting functions for the color difference adjustment considering the location variation of $L^{*}, a^{*}$, and $b^{*}$ coordinates (12).

\section{Statistical Analysis}

DC data was tested by normal distribution (Shapiro-Wilk test) and homoscedasticity (Levine test) followed by twoway ANOVA and Tukey tests $(\alpha=0.05)$. The color alteration data were tested by normal distribution (Shapiro-Wilk test) and homoscedasticity (Levine test) followed by two-way ANOVA and Tukey tests $(\alpha=0.05)$. For opacity data, two-way repeated measures ANOVA were applied for each composite resin $(\alpha=0.05)$. Linear regression for $\Delta \mathrm{E}_{\mathrm{ab}}$ and immediate and mediate composite DC data set were calculated.

\section{Results}

The DC (\%) mean and standard deviation values of the all tested composite resins are shown in Table 2. Two-way ANOVA showed that the composite resin $(p<0.01)$ and surface treatment $(p<0.01)$ and the interaction between both study factors $(p=0.005)$ were significant for $D C$ values. The moment of analysis had no influence in the DC values. Glycerin usage increased significantly $(p<0.001)$ the DC values for all composite resins.

The mean and standard deviation values of opacity before and after coffee storage, are shown in Table 3. Twoway ANOVA showed that the composite resin $(p=0.007)$, and moment of analysis $(\mathrm{p}<0.001)$ influenced significantly the opacity but not the interaction of them $(p=0.803)$. Microhybrid composite resin showed higher opacity, followed by the nanoparticle and bulk-fill composite resins, regardless of surface treatment.

The color changes for $L^{*}, a^{*}$ and $b^{*}$ parameters are shown in Figure 1 and the mean and standard deviation values of $\Delta \mathrm{E}_{\mathrm{ab}}$ and $\Delta \mathrm{E}_{00}$ after coffee storage, are shown in Table 4. Two-way ANOVA showed that the composite resin $\left(\Delta \mathrm{E}_{\mathrm{ab}}: \mathrm{p}<0.001 / \Delta \mathrm{E}_{00}: \mathrm{p}<0.001\right)$ and surface treatment factor $\left(\Delta \mathrm{E}_{\mathrm{ab}}: \mathrm{p}<0.001 / \Delta \mathrm{E}_{00}: \mathrm{p}=0.003\right)$ were significant; however, the interactions between both factors $\left(\Delta \mathrm{E}_{\mathrm{ab}}: \mathrm{p}=0.167\right)$ $\Delta \mathrm{E}_{00}: \mathrm{p}=0.38$ ) were not significant. In general, glycerin usage had not influence on the surface coffee staining for all composite resins. Finishing and polishing caused lowest 
$\Delta \mathrm{E}_{\mathrm{ab}}$ and $\Delta \mathrm{E}_{00}$ values, regardless of composite resins. Linear regression showed a very weak correlation between $\Delta \mathrm{E}_{00}$ and $D C\left(R^{2}=0.00548\right)$.

\section{Discussion}

In the present study, the DC of bulk-fill and conventional composite resins was affected by the glycerin usage and the color stability was influenced by the finishing and polishing procedures. Therefore, the null hypothesis of this study was rejected.

DC is the proportion of single carbon-carbon bonds in a polymer matrix to double carbon bonds between monomers (1). It has been shown that the clinical performance (13) of dental composites can be affected by mechanical properties that are influenced mainly by the DC (14), filler content and type of matrix $(13,15)$. Low DC values might have negative influence on fracture resistance, wear resistance, compressive strength and can lead to early replacement of long-term restorations caused by detachment or discoloration around the adhesive interfaces (16). Low DC values can also increase the release of toxic monomers and initiators in the oral environment $(5,17)$. In this study, a higher DC was observed for groups with oxygen inhibition surface treatment by glycerin, regardless of composite resins tested. During polymerization, oxygen reacts rapidly with free oxidized radicals and its presence slows the reaction. Oxygen inhibition improved polymerization of the surface layer (6). This aspect could also have impact on the surface hardness when the matrix band for making a direct restoration is removed after the light curing procedure $(5,6)$.

Low DC was observed in the control group and when composite materials were submitted only to finishing

Table 2. Mean and standard deviation of the degree of conversion (\%) for all composite resins, according to surface treatments and assessment time

\begin{tabular}{|c|c|c|c|c|c|c|}
\hline \multirow{2}{*}{ Surface treatment } & \multicolumn{2}{|c|}{ Bulk-fill } & \multicolumn{2}{|c|}{ Nanoparticle } & \multicolumn{2}{|c|}{ Microhybrid } \\
\hline & Immediate & Mediate & Immediate & Mediate & Immediate & Mediate \\
\hline Control & $45.5 \pm 6.1 \mathrm{Ba}$ & $52.0 \pm 2.4 \mathrm{Ba}$ & $31.0 \pm 3.8 \mathrm{Bb}$ & $31.4 \pm 7.9 \mathrm{Bb}$ & $43.5 \pm 7.4 \mathrm{Ba}$ & $44.0 \pm 9.1 \mathrm{Ba}$ \\
\hline Gly & $70.0 \pm 8.4 \mathrm{Ac}$ & $69.8 \pm 8.0 \mathrm{Aa}$ & $72.5 \pm 2.2 \mathrm{Abc}$ & $70.4 \pm 5.8 \mathrm{Aa}$ & $74.5 \pm 4.2 \mathrm{Aa}$ & $81.6 \pm 1.7 \mathrm{Aa}$ \\
\hline Gly + FP & $72.7 \pm 5.3 \mathrm{Aa}$ & $83.4 \pm 2.9 \mathrm{Aa}$ & $67.9 \pm 5.6 \mathrm{Ab}$ & $64.7 \pm 6.9 \mathrm{Aa}$ & $72.1 \pm 5.0 \mathrm{Aa}$ & $70.0 \pm 6.9 \mathrm{Aa}$ \\
\hline FP & $43.4 \pm 9.1 \mathrm{Ba}$ & $45.3 \pm 4.3 \mathrm{Ba}$ & $28.6 \pm 6.9 \mathrm{Bb}$ & $28.1 \pm 1.2 \mathrm{Ba}$ & $39.7 \pm 8.7 \mathrm{Bb}$ & $39.0 \pm 9.5 \mathrm{Ba}$ \\
\hline
\end{tabular}
Means followed by the different letters (uppercase for comparing the "surface treatment within assessment time for each composite resin - in
columns"; lowercase for comparing the "resins within each assessment- in rows") indicate significant difference at Tukey`s test (p<0.05). Gly:
glycerin; FP: finishing and polishing.

Table 3. Mean and standard deviation of opacity (\%) for all composite resins before and after coffee storage, according to surface treatments

\begin{tabular}{|c|c|c|c|c|c|c|c|c|c|}
\hline & \multicolumn{4}{|c|}{ Before coffee storage } & \multicolumn{4}{|c|}{ After coffee storage } & \multirow{2}{*}{$\begin{array}{c}\text { Pooled } \\
\text { averages }\end{array}$} \\
\hline & Control & Gly & Gly + FP & FP & Control & Gly & Gly + FP & FP & \\
\hline Bulk-fill & $67.5 \pm 1.2$ & $67.6 \pm 2.1$ & $68.7 \pm 1.2$ & $69.1 \pm 1.1$ & $81.4 \pm 1.7$ & $80.5 \pm 1.8$ & $81.6 \pm 1.0$ & $81.0 \pm 0.5$ & $74.7 \pm 6.7^{c}$ \\
\hline Nanoparticle & $75.0 \pm 0.8$ & $75.4 \pm 1.0$ & $75.2 \pm 1.7$ & $74.8 \pm 2.3$ & $88.6 \pm 1.9$ & $88.7 \pm 0.8$ & $88.8 \pm 2.1$ & $87.9 \pm 1.2$ & $81.7 \pm 6.9^{B}$ \\
\hline Microhybrid & $82.8 \pm 0.4$ & $82.6 \pm 0.9$ & $83.0 \pm 0.9$ & $83.5 \pm 0.5$ & $92.9 \pm 0.9$ & $92.2 \pm 0.8$ & $92.7 \pm 1.0$ & $93.7 \pm 0.8$ & $87.9 \pm 5.1^{A}$ \\
\hline $\begin{array}{l}\text { Pooled } \\
\text { averages }\end{array}$ & \multicolumn{4}{|c|}{$75.4 \pm 6.2^{b}$} & \multicolumn{4}{|c|}{$87.5 \pm 5.0^{a}$} & \\
\hline
\end{tabular}

For pooled averages, distinct letters (uppercase comparing composite resins, lowercase comparing assessment times) indicate statistical difference at Tukey's test $(p<0.05)$. There is not a statistically significant difference between surface treatments. Gly: glycerin; FP: finishing and polishing.

Table 4. Means and standard deviation of the color difference $\left(\Delta \mathrm{E}_{\mathrm{ab}}\right.$ and $\left.\Delta \mathrm{E}_{00}\right)$ after storage in coffee, according to surface treatments and composite resins

\begin{tabular}{|c|c|c|c|c|c|c|}
\hline \multirow{2}{*}{$\begin{array}{l}\text { Surface } \\
\text { treatment }\end{array}$} & \multicolumn{2}{|c|}{ Microhybrid } & \multicolumn{2}{|c|}{ Nanoparticle } & \multicolumn{2}{|c|}{ Bulk-Fill } \\
\hline & $\Delta \mathrm{E}_{\mathrm{ab}}$ & $\Delta \mathrm{E}_{00}$ & $\Delta \mathrm{E}_{\mathrm{ab}}$ & $\Delta \mathrm{E}_{00}$ & $\Delta \mathrm{E}_{\mathrm{ab}}$ & $\Delta \mathrm{E}_{00}$ \\
\hline Control & $19.9 \pm 0.9^{\mathrm{Ba}}$ & $16.2 \pm 0.7^{\mathrm{Ba}}$ & $24.4 \pm 0.9^{\mathrm{Bb}}$ & $20.5 \pm 1.0^{\mathrm{Bb}}$ & $24.9 \pm 1.7^{\mathrm{Bb}}$ & $20.3 \pm 1.6^{\mathrm{Bb}}$ \\
\hline Gly & $19.4 \pm 1.0^{\mathrm{Ba}}$ & $16.4 \pm 1.2^{\mathrm{Ba}}$ & $24.2 \pm 0.8^{\mathrm{Bb}}$ & $20.2 \pm 0.6^{\mathrm{Bb}}$ & $23.5 \pm 1.3^{\mathrm{Bb}}$ & $19.4 \pm 1.0^{\mathrm{Bb}}$ \\
\hline Gly + FP & $20.6 \pm 1.7^{\mathrm{ABa}}$ & $17.0 \pm 1.6^{\mathrm{ABa}}$ & $23.6 \pm 1.0^{\mathrm{ABb}}$ & $19.6 \pm 0.8^{\mathrm{ABb}}$ & $22.1 \pm 0.5^{\mathrm{ABb}}$ & $18.4 \pm 0.4^{\mathrm{ABb}}$ \\
\hline FP & $18.7 \pm 2.6^{\mathrm{Aa}}$ & $15.3 \pm 2.3^{\mathrm{Aa}}$ & $22.4 \pm 1.0^{\mathrm{Ab}}$ & $18.6 \pm 0.8^{\mathrm{Ab}}$ & $21.7 \pm 1.0^{\mathrm{Ab}}$ & $18.1 \pm 0.8^{\mathrm{Ab}}$ \\
\hline
\end{tabular}

For values of color parameters $\left(\Delta \mathrm{E}_{\mathrm{ab}}\right.$ or $\Delta \mathrm{E}_{00}$ ) different letters (uppercase for comparing the surface treatment - in columns; lowercase for comparing composite resin - in rows) indicate significant difference at Tukey`s test $(p<0.05)$. Gly: glycerin; FP: finishing and polishing. 

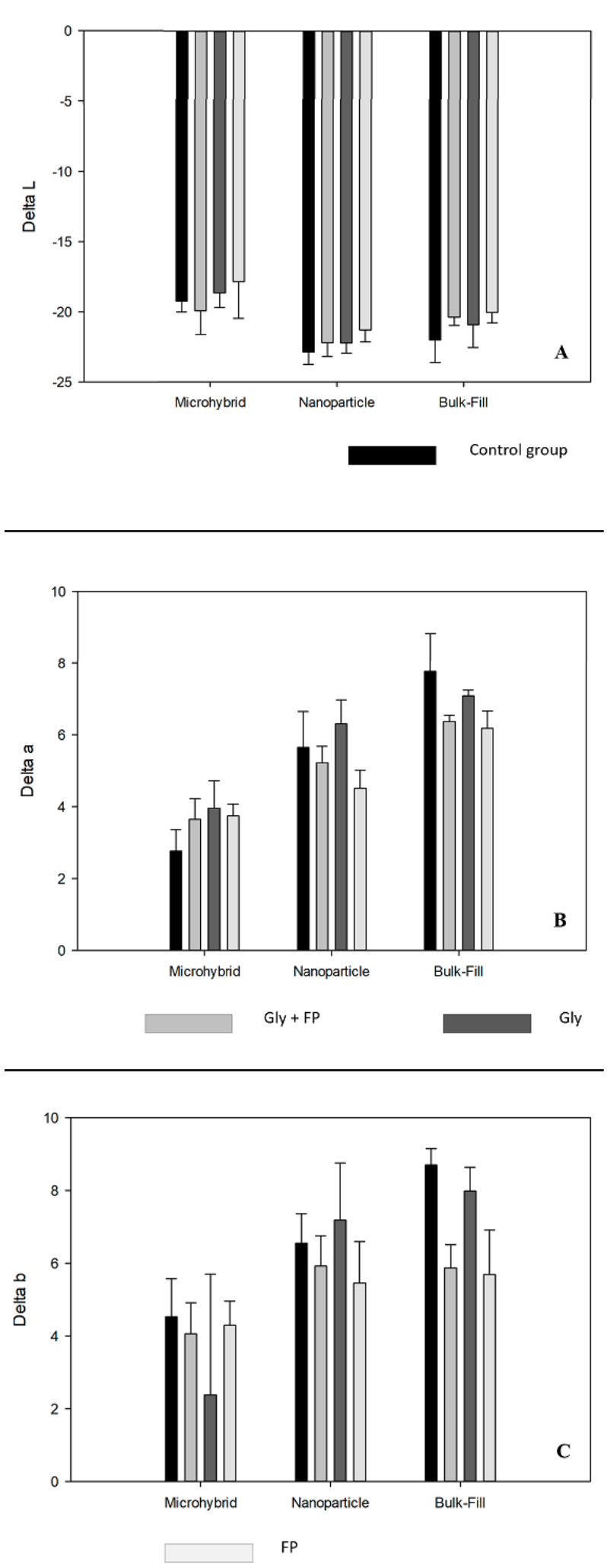

Figure 1. Color changes of composite resins after storage in coffee, according surface treatments. Arepresents the change lightness within a specimen and ranges from 0 (black) to 100 (white). $\mathrm{B}=$ represents the change of degree of green/red measurement and $\mathrm{C}$ represents the degree of blue/yellow color change of composite resins after the storage in coffee. and polishing protocol. Also, these data were lower than the literature reports $(3,1)$. In this research, one possible explanation for this phenomenon may be related to the fact that a polyester strip was used to obtain a flat surface but it was removed before photoactivation, allowing contact between the resin and oxygen. Additionally, maybe finishing and the polishing protocol was not able to completely remove the unpolymerized resin layer, resulting in a lower $\mathrm{DC}$ in the resin composite surface.

However, finishing and polishing (5) surface procedures can reduce color variation $\left(\Delta \mathrm{E}_{\mathrm{ab}}\right.$ and $\left.\Delta \mathrm{E}_{00}\right)$ after immersion in coffee. The esthetic features of restorations should not be defined as a factor indicating some intervention in posterior restorations. However, it is well-known that resin staining remains a cause of re-intervention even in posterior teeth, and more color-stable composites can prevent over-interventions. In case finish and polish procedures are awkward to achieve in posteriors composite restoration, light-curing in the absence of oxygen should be considered, especially when performing composite restoration in esthetic areas or in areas difficult to access such as the proximal surfaces.

Instrumental techniques for measuring color alteration include colorimetry and spectrophotometry, with good reliable performance for dental materials. Spectrophotometry is more accurate than measuring by using colorimeter, which is not influenced by ambient light (2). For the objective color difference measurement in dentistry, the CIELAB color difference formula has been extensively used, allowing for comparison with previous similar studies on dental composites. It assumes the uniformity of CIELAB color space and the equal importance of CIELAB individual parameters $\left(L^{*}, a^{*}\right.$, and $\left.b^{*}\right)$. However, a discrepancy sensitivity on the $L^{*}, a^{*}$, and $b^{*}$ parameters has been demonstrated concerning visual perceptibility and acceptability thresholds.(12,19). The CIEDE2000 metrics have also been then proposed due better indicative of human visual thresholds, even closer with the adjustment of parametric factor $\mathrm{KL}, \mathrm{KC}$, and $\mathrm{KH}$ set $(2: 1: 1)$ (12). Similar results were observed for both color difference parameters in this research.

In the present study, microhybrid composite resin storage for 15 days in coffee had different performance, in terms of color change than conventional nanoparticle or bulk-fill composite resins, regardless of surface treatment. The difference in staining may be attributed to the composition of the materials and the characteristics of the particles. The hydrophilicity and degree of water sorption of a resin matrix could affect the staining susceptibility of resin composites. Although the particle sizes of nanoparticle resin composite smaller than microhybrid, it is expected to show less water sorption, thus less $\Delta \mathrm{E}$. The discrepancy 
could be due to resin matrices and additives such as dyes, photosensitizer molecules, and other chemicals in these materials. Moreover, both bulk-fill and nanoparticle (enamel shade) have high translucency and hightranslucent materials had the lowest color stability (19)

The aging process was simulated to examine changes in the color alteration of the composite resins over time $(14,16,20)$. In vitro studies evaluating color stability have examined composite specimens immersed in staining solutions over a particular period of time $(9,14,16)$. Some beverages can alter the color of composite resins through the absorption and/or adsorption of colorants during the period of exposure $(9,21)$. In most studies, the specimens have been immersed in coffee, grape juice, wine, and other beverages continuously for long periods of time (hours or days) $(3,9)$. However, the exposure of composite restorations to beverages in vivo occurs through several cycles of a few seconds each. The temperature of a beverage can also increase its staining effect, as volumetric changes caused by heat or cold affect possible specimen defects (22)

For most restorative materials, there is a complex process in the oral environment that includes disintegration and dissolution in saliva and other types of physical/chemical degradation, such as wear and erosion caused by food and drinks, chewing, and bacterial activity $(9,17)$. This study demonstrated that bulk-fill composite resin storage for 15 days in coffee had different performance, in terms of opacity, than conventional composite resins, regardless of surface treatment. While there is a less evident change in the chemical composition in bulk-fill and conventional composites, the enhanced depth of cure in several bulk-fill is not a result of an improved refractive index mismatch between resin and filler but seems rather have been carried out by reducing the amount of pigments and enlarging the filler size. The higher level of translucency already characteristic of bulk-fill and nanoparticle resins may be responsible for the lower opacity values than microhybrid resin.

More studies are still necessary, especially clinical trials, with real time follow-up. Additionally, in laboratorial study should perform thermal/mechanical fatigue, wettability, water sorption and solubility, the thickness of the unpolymerized surface layer, biofilm presence for degradation and cumulative deleterious effects, to better respond to the dilemma of long-term maintenance of restorative materials after oxygen inhibition and also the consequence of the finishing and polishing procedures. The degradation can be prolonged by the maintenance of a low $\mathrm{pH}$ in the oral cavity $(9,23)$. Associated with stains produced by immersion in drinks such as coffee, this aspect may also contribute to marginal discoloration, which is wrongly defined as the main reason for the replacement of esthetics restorations $(18,24,25)$

In this study, it was simulated the effect of intermittent usage of coffee on the composite resins. The immersion of coffee negatively influenced the physical and chemical properties of the composite resins tested. To maintain the esthetic performance of composite resin restoration, it is suggested to make finishing and polishing surface procedures after conclude the restorative procedure. It is an important indicator to reduce the possibility of changing color parameters and could prevent degradation and darkening of composite resins. Furthermore, patients should be informed about the deleterious effects caused by the abusive use of coffee solutions on composite resin restorations.

The clinical significance of this study is that the degree of conversion of the composite resins surface can be improved by using glycerin to reduce the oxygen presence and the surface staining can be reduced if this previous procedure is associated with immediate finishing and polishing procedures. Within the limits imposed in the experimental design, it is possible to conclude that the glycerin usage increased the degree of conversion and had no effect on the surface coffee staining of tested composite resins and the finishing and polishing surface procedures reduced significantly the color variation $\left(\Delta \mathrm{E}_{\mathrm{ab}} / \Delta \mathrm{E}_{00}\right)$ on the surface of bulk-fill and conventional composite resins.

\section{Resumo}

Este estudo investigou os efeitos da inibição de oxigênio e dos procedimentos de acabamento/polimento nas propriedades das resinas compostas. Foram avaliadas uma resina composta bulk fill e duas resinas convencionais (nanoparticulada e microhibrida). Os espécimes foram confeccionados, variando o tratamento de superficie: controle, sem tratamento; glicerina (inibidor de oxigênio); acabamento e polimento; glicerina + acabamento e polimento. 0 grau de conversão (GC) foi medido pela Espectroscopia de Infravermelho Transformada de Fourier (FIIR) imediatamente e após 15 dias da confecção dos espécimes $(n=5)$. Os índices de alteração de $\operatorname{cor} \Delta \mathrm{E}_{\mathrm{ab}}$, $\Delta \mathrm{E}_{00}$ e opacidade foram avaliados por meio de espectrofotômetro, após 15 dias de imersão no café, utilizando o sistema CIELAB $(\mathrm{n}=5)$. Os dados da alteração da cor foram analisados pelos testes ANOVA de dois fatores e Tukey $(\alpha=0,05)$ e a opacidade por ANOVA de medidas repetidas. O uso de glicerina aumentou significativamente o GC, no entanto, não teve influência sobre os valores $\Delta \mathrm{E}_{\mathrm{ab}}$ e $\Delta \mathrm{E}_{00}$. $\mathrm{O}$ acabamento e o polimento reduziram os valores de $\Delta \mathrm{E}_{\mathrm{ab}}$ e $\Delta \mathrm{E}_{00}$, independentemente da resina composta. A resina microhíbrida apresentou maior opacidade, seguida pela nanoparticula e bulk-fill, independentemente do tratamento de superfície. O acabamento e polimento resultou em menor grau de conversão das resinas compostas se comparado ao uso de um agente inibidor de oxigênio (glicerina), porém apresenta resultados similares para a pigmentação pelo café.

\section{Acknowledgments}

This study was financed in part by the Coordination of Superior Level Staff Improvement - CAPES /(Finance Code 001) and the Research Supporting Foundation of Minas Gerais State - FAPEMIG (Finance Code 11311).

\section{References}

1. Velo MM de AC, Wang L, Furuse AY, Brianezzi LF de F, Scotti CK, Zabeu $\mathrm{GS}$, et al. Influence of modulated photo-activation on shrinkage 
stress and degree of conversion of bulk-fill composites. Braz Dent J 2019:30:592-598.

2. Ozera EH, Pascon FM, Correr AB, Puppin-Rontani RM, de Castilho AR, Correr-Sobrinho $L$, et al. Color stability and gloss of esthetic restorative materials after chemical challenges. Braz Dent J 2019;30:52-57.

3. Al Kheraif AAA, Qasim SS Bin, Ramakrishnaiah R, Rehman I ur. Effect of different beverages on the color stability and degree of conversion of nano and microhybrid composites. Dent Mater J 2013;32:326-331.

4. Soares CJ, Rodrigues MP, Oliveira LRS, Braga SSL, Barcelos LM, Da Silva $\mathrm{GR}$, et al. An evaluation of the light output from 22 contemporary light curing units. Braz Dent J 2017;28:362-371.

5. Marigo L, Nocca G, Fiorenzano G, Calla C, Castagnola R, Cordaro M, et al. Influences of different air-inhibition coatings on monomer release, microhardness, and color stability of two composite materials. Biomed Res Int 2019;2019:4240264.

6. Aromaa MK, Vallittu PK. Delayed post-curing stage and oxygen inhibition of free-radical polymerization of dimethacrylate resin. Dent Mater 2018;34:1247-1252.

7. Sahadi BO, Price RB, Andre CB, Sebold M, Bermejo GN, PalmaDibb $R G$, et al. Multiple-peak and single-peak dental curing lights comparison on the wear resistance of bulk-fill composites. Braz Oral Res 2018;32:e122.

8. Braga $S$, Oliveira L, Ribeiro M, Vilela A, da Silva GR, Price RB, et al. Effect of Simulated Pulpal Microcirculation on Temperature When Light Curing Bulk Fill Composites. Oper Dent 2019;44:289-301.

9. Borges MG, Soares CJ, Maia TS, Bicalho AA, Barbosa TP, Costa HL, et al. Effect of acidic drinks on shade matching, surface topography, and mechanical properties of conventional and bulk-fill composite resins. J Prosthet Dent 2019;121:868.e1-868.e868.

10. Oliveira LRS, Braga SSL, Bicalho AA, Ribeiro MTH, Price RB, Soares CJ. Molar cusp deformation evaluated by micro-CT and enamel crack formation to compare incremental and bulk-filling techniques. J Dent 2018;74:71-78.

11. Araujo FS, Barros MCR, Santana MLC, de Jesus Oliveira LS, Silva PFD, Lima $\mathrm{G}$ da $\mathrm{S}$, et al. Effects of adhesive used as modeling liquid on the stability of the color and opacity of composites. J Esthet Restor Dent 2018;30:427-433.

12. Miotti LL, Santos IS, Nicoloso GF, Pozzobon RT, Susin AH, Durand LB. The use of resin composite layering technique to mask discolored background: A CIELAB/CIEDE2000 analysis. Oper Dent 2017;42:165174.

13. Alzraikat $H$, Burrow MF, Maghaireh GA, Taha NA. Nanofilled resin composite properties and clinical performance: a review. Oper Dent 2018;43:E173-190

14. Oliveira DCRS de, Souza-Junior EJ, Prieto LT, Coppini EK, Maia RR,
Paulillo LAMS. Color stability and polymerization behavior of direct esthetic restorations. J Esthet Restor Dent 2014;26:288-295.

15. Cidreira Boaro LC, Pereira Lopes D, de Souza ASC, Lie Nakano E, Ayala Perez MD, Pfeifer CS, et al. Clinical performance and chemical-physical properties of bulk fill composites resin -a systematic review and metaanalysis. Dent Mater 2019;35:e249-264.

16. Prieto LT, Pimenta de Araujo CT, Araujo Pierote JJ, Salles de Oliveira DCR, Coppini EK, Sartini Paulillo LAM. Evaluation of degree of conversion and the effect of thermal aging on the color stability of resin cements and flowable composite. J Conserv Dent 2018;21:47-51.

17. Candea Ciurea A, Surlin P, Stratul S-I, Soanca A, Roman A, Moldovan $M$, et al. Evaluation of the biocompatibility of resin composite-based dental materials with gingival mesenchymal stromal cells. Microsc Res Tech. 2019;82:1768-1778.

18. Paravina $R D$, Ghinea $R$, Herrera $L$, Bona $A D$, Igiel $C$, Linninger $M$, et al. Color difference thresholds in dentistry. J Esthet Restor Dent 2015;27:S1-9

19. Salgado VE, Rego GF, Schneider LF, Moraes RR, Cavalcante LM. Does translucency influence cure efficiency and color stability of resin-based composites? Dent Mater 2018;34:957-966

20. Roselino L de MR, Chinelatti MA, Alandia-Roman CC, Pires-de-Souza $\mathrm{F}$ de CP. Effect of brushing time and dentifrice abrasiveness on color change and surface roughness of resin composites. Braz Dent $J$ 2015;26:507-513.

21. Alberton Da Silva V, Alberton Da Silva S, Pecho OE, Bacchi A. Influence of composite type and light irradiance on color stability after immersion in different beverages. J Esthet Restor Dent 2018;30:390-396.

22. Ren $Y-F$, Feng $L$, Serban D, Malmstrom HS. Effects of common beverage colorants on color stability of dental composite resins: the utility of a thermocycling stain challenge model in vitro. J Dent 2012;40:e48-56.

23. Somacal DC, Manfroi FB, Monteiro M, Oliveira SD, Bittencourt $H R$, Borges $G A$, et al. Effect of $\mathrm{pH}$ cycling followed by simulated toothbrushing on the surface roughness and bacterial adhesion of bulk-fill composite resins. Oper Dent 2020;45:209-218.

24. Demarco FF, Collares K, Coelho-de-Souza FH, Correa MB, Cenci MS, Moraes RR, et al. Anterior composite restorations: A systematic review on long-term survival and reasons for failure. Dent Mater 2015:31:1214-24.

25. Demarco FF, Correa MB, Cenci MS, Moraes RR, Opdam NJM. Longevity of posterior composite restorations: not only a matter of materials. Dent Mater 2012;28:87-101

Received August 7, 2020 Accepted September 21, 2020 